University of Montana

ScholarWorks at University of Montana

$11-2010$

\title{
Disappearing Plants: Why They Hide and How They Return
}

Jennifer R. Gremer

Anna Sala

University of Montana - Missoula, sala@mso.umt.edu

Elizabeth E. Crone

Follow this and additional works at: https://scholarworks.umt.edu/biosci_pubs

Part of the Biology Commons

Let us know how access to this document benefits you.

\section{Recommended Citation}

Gremer, Jennifer R.; Sala, Anna; and Crone, Elizabeth E., "Disappearing Plants: Why They Hide and How They Return" (2010). Biological Sciences Faculty Publications. 319.

https://scholarworks.umt.edu/biosci_pubs/319

This Article is brought to you for free and open access by the Biological Sciences at ScholarWorks at University of Montana. It has been accepted for inclusion in Biological Sciences Faculty Publications by an authorized administrator of ScholarWorks at University of Montana. For more information, please contact

scholarworks@mso.umt.edu. 


\title{
Notes
}

\section{Disappearing plants: why they hide and how they return}

\author{
Jennifer R. Gremer, ${ }^{1,3}$ Anna Sala, ${ }^{1}$ and Elizabeth E. Crone ${ }^{2}$ \\ ${ }^{1}$ Division of Biological Sciences, University of Montana, Missoula, Montana 59812 USA \\ ${ }^{2}$ Wildlife Biology Program, College of Forestry and Conservation, University of Montana, Missoula, Montana 59812 USA
}

\begin{abstract}
Prolonged dormancy is a life-history stage in which mature plants fail to resprout for one or more growing seasons and instead remain alive belowground. Prolonged dormancy is relatively common, but the proximate causes and consequences of this intriguing strategy have remained elusive. In this study we tested whether stored resources are associated with remaining belowground, and investigated the resource costs of remaining belowground during the growing season. We measured stored resources at the beginning and end of the growing season in Astragalus scaphoides, an herbaceous perennial in southwest Montana, USA. At the beginning of the growing season, dormant plants had lower concentrations of stored mobile carbon (nonstructural carbohydrates, NSC) than did emergent plants. Surprisingly, during the growing season, dormant plants gained as much NSC as photosynthetically active plants, an increase most likely due to remobilization of structural carbon. Thus, low levels of stored NSC were associated with remaining belowground, and remobilization of structural carbon may allow for dormant plants to emerge in later seasons. The dynamics of NSC in relation to dormancy highlights the ability of plants to change their own resource status somewhat independently of resource assimilation, as well as the importance of considering stored resources in understanding plant responses to the environment.
\end{abstract}

Key words: Astragalus scaphoides; carbon metabolism; life history; nonstructural carbohydrates, prolonged dormancy; stored resources; vegetative dormancy.

\section{INTRODUCTION}

Prolonged dormancy is a relatively common stage in herbaceous perennial plants in which mature plants remain belowground during one or more entire growing seasons instead of emerging to grow and acquire resources (Lesica and Steele 1994). Interestingly, prolonged dormancy occurs in many unrelated species, suggesting that it is a strategy that has evolved many times (Lesica and Steele 1994). Prolonged dormancy has been most frequently observed in the Orchid family, but it has been reported in over 10 plant families and 52 species of plants (Lesica and Steele 1994, Shefferson 2009). Despite the fact that it is relatively common, the causes and consequences for this behavior remain unclear. Why do some plants forego the opportunity to grow and reproduce, while others resume seasonal activity? Here we investigate the proximate causes and

Manuscript received 9 October 2009; revised 8 March 2010; accepted 10 March 2010. Corresponding Editor: N. Underwood.

${ }^{3}$ E-mail: jennifer.gremer@mso.umt.edu consequences of prolonged dormancy in a long-lived native perennial, Astragalus scaphoides.

Prolonged dormancy (also known as "vegetative dormancy"; see Lesica and Steele 1994, Shefferson 2009) is different from other, more extensively studied types of plant dormancy. The metabolic costs of maintaining mature plant parts belowground during prolonged dormancy are likely higher than costs of seed dormancy. Further, in contrast to seasonal dormancy, where all individuals go dormant, prolonged dormancy often involves only a fraction of individuals in any given year. The lack of photosynthesis and reproduction by individuals undergoing prolonged dormancy could have large negative fitness impacts. However, the prevalence of this strategy suggests either neutral or even positive effects. For instance, prolonged dormancy may allow individuals to avoid large resource demands or risks (e.g., biotic or abiotic stress) associated with growing aboveground tissues (Shefferson 2009). To date, little is known about what causes certain individuals to remain belowground while others are able to grow and 
reproduce aboveground, or about the costs and benefits of doing so.

Two leading hypotheses have been proposed to explain prolonged dormancy: (1) it occurs in response to external cues, such as herbivory or drought (Morrow and Olfelt 2003, Shefferson et al. 2003, 2005a, Miller et al. 2004, Lesica and Crone 2007), and (2) plants remain belowground because they lack resources to build leaves (Shefferson et al. 2005a, Shefferson et al. 2006). If prolonged dormancy occurs in response to some critical limiting resource, then plants must gain this resource while dormant so they can emerge in later years. However, plants typically lose stored resources during the non-growing season due to metabolic demands and lack of photosynthesis (Wyka 1999). Prolonged dormancy could incur a similar or even greater resource cost. Plants that are dormant during the summer miss a season of carbon gain through photosynthesis, and likely lose even more carbon to respiration in summer than in winter due to higher soil temperatures (Amthor 2000). If so, prolonged dormancy would be a costly life stage because plants need remaining stored resources to survive another winter, as well as to initiate seasonal growth and reproduction. Such resource costs could have significant impacts on future performance and, ultimately, on fitness. It is possible that metabolism during prolonged dormancy may fundamentally differ from dormancy during winter and drought, or that individuals that remain dormant during the growing season may gain resources through belowground processes. To date, no one has tested these alternatives by directly measuring the dynamics of stored resources in dormant plants.

We investigated the causes and consequences of prolonged dormancy by measuring stored resources. of plants at different life history stages in a long-lived perennial wildflower, Astragalus scaphoides. We emphasized stored resources not only because they are a component of one of the leading hypotheses for prolonged dormancy but also because they reflect current condition as well as integrate past performance such as resource capture and allocation to various lifehistory functions (Chapin et al. 1990, Crone et al. 2009). Stored resources are critical for numerous plant functions, including plant growth following winter dormancy, reproduction, recovery from herbivory, and survival (Mooney and Hays 1973, Ho and Rees 1976, Chapin et al. 1990, Boyce and Volenec 1992, Zimmerman and Whigham 1992, Van der Heyden and Stock 1996, Kobe 1997, Wyka 1999). Furthermore, stored resources play critical roles in signaling pathways that control plant growth and development (Halford and Paul 2003, Rolland et al. 2006, Lee et al. 2007). Here, we asked: (1) Are stored resources associated with the entry into prolonged dormancy? (2) What are the resource consequences of remaining belowground during otherwise favorable conditions? If prolonged dormancy is associated with stored resources, we expect that dormant plants will be lacking in one or more stored resources at the beginning of the growing season. If prolonged dormancy is similar to other types of dormancy, such as winter dormancy, we expect dormant plants to deplete stored resources over the growing season. However, if prolonged dormancy differs fundamentally from other types of dormancy, dormant plants may be able to conserve or acquire stored resources during the growing season.

\section{Methods}

\section{Study species}

Astragalus scaphoides (Fabaceae) is an iteroparous legume with a long, narrow taproot, found on southfacing slopes in high-elevation sagebrush steppe communities (Lesica 1995). It has an estimated life span of 21 years (Ehrlen and Lehtila 2002), and does not reproduce vegetatively (Lesica 1995). On average, 20\% of the individuals in our population are dormant in any given year (Crone and Lesica 2004) and dormancy events typically last one year. Dormancy is weakly correlated $(0.2<r<0.3)$ with warm, dry weather in the spring (J. Gremer, unpublished analyses). However, even in years of high dormancy, only a portion of individuals remain dormant while the rest emerge as vegetative or reproductive plants. Plants flower approximately in alternate years (Lesica 1995, Crone et al. 2005), and this strategy is driven by fluctuations in stored resources rather than changes in climate (Crone et al. 2005, 2009). Plants that do not flower may produce leaves and be vegetative, or remain dormant during the growing season.

If plants emerge aboveground, they initiate growth in April, and biomass senesces back to perennating roots in early July. Mature dormant plants can be located by dried flowering stalks that persist aboveground for 2-3 years. Evidence of previous flowering events can be seen on root crowns, because the flowering stalks leave scars that are apparent even after several years.

\section{Harvests}

Sampling took place during 2006-2008 at Sheep Corral Ridge, located in Beaverhead County in southwestern Montana, USA $\left(45^{\circ} 06^{\prime} 55^{\prime \prime} \mathrm{N}, 113^{\circ} 02^{\prime} 58^{\prime \prime} \mathrm{W}\right)$. The climate is semiarid; mean annual precipitation is 250 $\mathrm{mm}$, with peak rainfall in May (Crone and Lesica 2006). The 10 upper $\mathrm{cm}$ of taproot (closest to the soil surface) from randomly selected dormant, vegetative, and reproductive plants $(n=$ between 5 and 7 plants per life stage) were destructively harvested in early May each year, as soon as the three stages could be clearly distinguished. In 2007 and 2008 roots were also harvested at the end of the growing season in July, after 
aboveground biomass of emergent plants had senesced. While we could not control for the age of dormant plants, we harvested only reproductively mature individuals (as evidenced on root crown, see Study species, above). Because it is not possible to sample these narrow tap roots nondestructively, the fate of harvested plants could not be followed through time.

Astragalus scaphoides plants emerge over several weeks in April. Dormant, vegetative, and reproductive plants can be clearly distinguished from each other in early May, when any plants that have not initiated growth will remain dormant. Since stored-resource dynamics may not only vary in dormant plants, but are also expected to vary depending on whether plants are reproductive or vegetative, we conducted harvests in early May to compare stored resources among the three life stages. However, by early May, plants have already grown a bit and may have assimilated carbohydrates through photosynthesis. To account for potential changes in stored carbon from the time of early emergence to the time when reproductive plants start to develop flower buds, we conducted a "pre-season" harvest of plants starting to emerge in April of 2007 (hereafter, "emergents"). All samples were stored on ice for transport to the laboratory. Roots were analyzed for nonstructural carbohydrates (NSC), nitrogen (N), and phosphorus (P). In 2007 and 2008 dormant roots were analyzed for total carbon, which includes both structural and mobile carbon compounds. All root tissue was analyzed for total carbon in 2008.

Immediately upon arrival in the laboratory, samples were heated in a microwave oven at $600 \mathrm{~W}$ for $60 \mathrm{sec}$ to denature enzymes. Samples were then oven dried to constant mass at $75^{\circ} \mathrm{C}$, ground to a fine powder, and stored at $4^{\circ} \mathrm{C}$. Total nonstructural carbohydrates (NSC) analyses were performed, following methods described in Hoch et al. (2002). In brief, a subsample of extract from boiled and centrifuged ground material is treated with isomerase and invertase to convert sucrose and fructose into glucose. The total amount of glucose (total free sugars) is then determined photometrically in a 96well plate reader, after enzymatic conversion to gluconate-6-P. The remainder extract is incubated with a dialysed crude fungal amylase to break down starch to glucose. Glucose is then determined as above. Starch is the difference of NSC minus free sugars. Ground, dried roots were sent to the Stable Isotope Laboratory, University of California, Davis, California, USA for analyses of $\mathrm{N}$ concentrations. There, samples were combusted at $1020^{\circ} \mathrm{C}$ in a reactor and $\mathrm{N}$ and carbon were determined by a continuous-flow isotope ratio mass spectrometer (IRMS; model ELx800; BioTek, Winooski, Vermont, USA). The 2007 samples were sent to the Colorado State University Soil Plant and Water Testing Laboratory (Fort Collins, Colorado, USA), where a nitric acid-perchloric acid digest was conducted to analyze $\mathrm{P}$ concentrations (Miller and KotubyAmacher 1996). Because P did not appear to have any major role (see Results, below) samples from 2008 were not sent for $\mathrm{P}$ analysis.

Since $A$. scaphoides has long narrow taproots $(<1 \mathrm{~cm}$ in diameter and $>1 \mathrm{~m}$ deep), sampling the entire root system is excessively destructive, so we harvested only the top $10 \mathrm{~cm}$ of root. We tested whether this sample was a good indicator of stored resources in the entire root system by conducting a limited number of fullroot harvests. In 2007, we conducted two harvests $(n=$ 5 roots, each) and excavated all root tissue. These samples were analyzed for NSC, N, and P. Total resource pools and concentration values for the top 10 $\mathrm{cm}$ of the root were highly correlated with those for the rest of the root tissue $\left(R^{2}=0.98\right.$ or higher). Further, root diameter was highly correlated with total biomass $\left(R^{2}=0.982, P=0.003\right)$ and we saw no significant differences among life stages in size at the beginning (ANOVA; $F_{2,23}=1.195, P=0.32$ ), or the end (ANOVA; $F_{3,30}=2.08, P=0.14$ ) of the season. Therefore, our harvests were representative of stored resources throughout the root, and not biased by plant size. These relationships allowed us to calculate total resource pools. Total resource-pool data followed the same trends as concentration data and, for simplicity, are not presented here.

\section{Statistical analyses}

All statistical analyses were conducted using $\mathrm{R}$ statistical software (R Development Core Team 2008). We used ANOVAs, with year and stage as factors and their interaction, to compare stored resources among life stages at the beginning of the season. We conducted the same analysis to compare stored resources at the end of the season. Tukey's honest significant difference (hsd) test was used as a post hoc comparison of mean resources among life stages at a given time. We then used general linear models with stage and time as independent variables to estimate the change in resource concentrations throughout the growing season for each life stage (normal distribution with identity link). Inspection of residuals confirmed that assumptions of general linear models were met.

RESUlts

\section{Nonstructural carbohydrates (NSC)}

Dormant plants began the season with lower concentrations of NSC, but ended the season with NSC levels comparable to emergent plants. At the beginning of the season (in May) dormant plants had significantly lower concentrations of NSC, relative to vegetative and reproductive plants (Fig. 1A; ANOVA; stage $F_{2,16}=$ 22.78, $P<0.001)$. NSC concentrations did not differ among years (ANOVA; year $F_{2,16}=1.49, P=0.24$ ). Lower NSC in dormant plants was not attributable to 

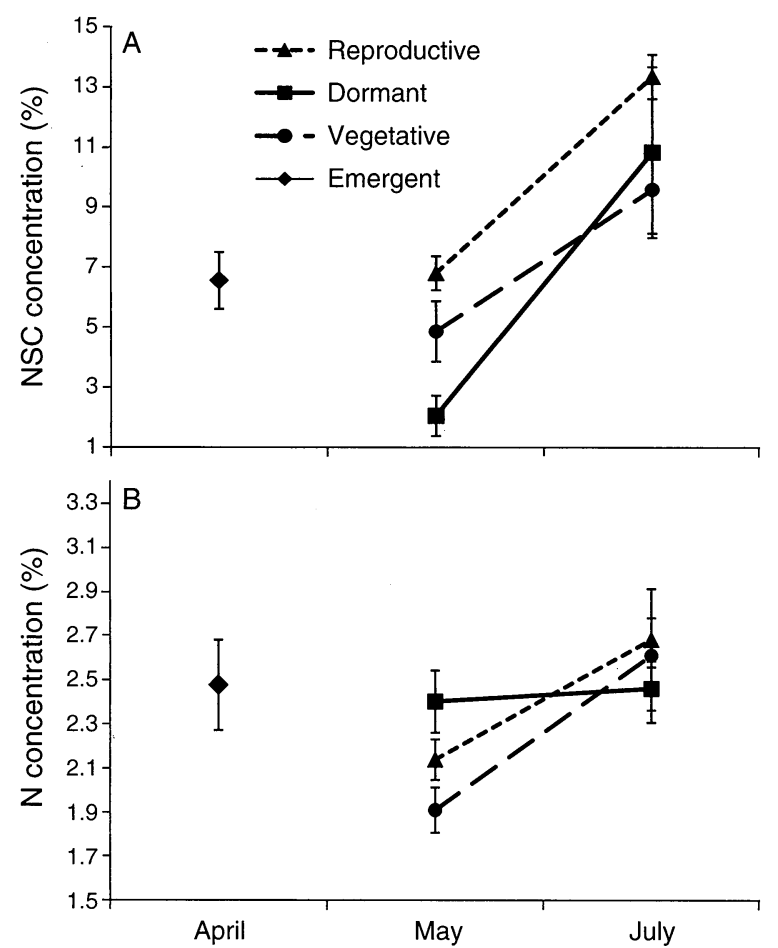

FIg. 1. Concentration dynamics of stored nonstructural carbohydrates (NSC) and nitrogen (N) concentrations over all life stages (emergent, reproductive, dormant, and vegetative) for Astragalus scaphoides, an herbaceous perennial in southwest Montana, USA. Data are means \pm SE, averaged over 2006 2008. (A) Dynamics of NSC. Dormant plants began the season with low NSC concentrations and increased concentrations over the growing season. (B) Nitrogen dynamics. Dormant plants had higher $\mathrm{N}$ concentrations at the beginning of the season but did not gain $\mathrm{N}$ through the season.

photosynthetic carbon gain by reproductive and vegetative plants from early emergence to May; NSC concentrations in emergent plants in April were not significantly different from those of reproductive or vegetative plants in May (Tukey's hsd, $P=0.84$ and $P=$ 0.18 , respectively). However, they were significantly higher than those of dormant plants in May (Tukey's hsd, $P=0.001$ ).

Over the growing season, NSC concentrations increased for all life stages (reproductive, vegetative, and dormant) (Fig. 1A). Dormant plants gained an average $8.0 \%$ (95\% CI [5.48-10.52]), an increase that was greater than vegetative and reproductive plants, although differences were not statistically significant (vegetative $P=0.08$, reproductive $P=0.42$ ). The increase of NSC in dormant plants was not associated with an increase in total carbon concentration (Fig. 2A), which did not significantly change over the season for any life stages (dormant, 95\% CI [-0.92-2.73]; vegetative, 95\% CI [-3.91-0.95]; reproductive, 95\% CI [-1.65-2.94]). There were no differences in total carbon concentrations among life stages (ANOVA; for stage: $F_{2,26}=1.933, P$ $=0.17$; for time $F_{1,27}=2.616, P=0.12$; for time $\times$ stage $F_{2,26}=2.374, P=0.12$ ). Increases in NSC were driven by sucrose concentrations, the main transport sugar in plants (Fig. 2B, average gain $=6.9 \%$, 95\% CI $[4.13$ 9.66]). At the end of the season, NSC concentrations did not differ among life stages (ANOVA; stage $F_{2,35}=2.54$, $P=0.10)$

\section{Nitrogen and phosphorus}

Dormant plants were not depleted in either $\mathrm{N}$ or $\mathrm{P}$ at the beginning of the season, and they did not gain mineral nutrients during the growing season. Dormant plants had higher $\mathrm{N}$ content than both reproductive and vegetative plants at the beginning of the season (Fig. 1B, ANOVA; stage $F_{2,16}=7.72, P<0.001$ ). However, they did not gain $\mathrm{N}$ during the season $(95 \%$ CI $[-0.301$, $0.300])$ while reproductive and vegetative plants did (reproductive 95\% CI [0.27, 0.82], vegetative 95\% CI $[0.43,0.98])$. These patterns were not affected by year (ANOVA; year $F_{1,16}=0.005, P=0.94$ ). There were no differences in $\mathrm{P}$ content among life stages at the beginning of the season (ANOVA; stage $F_{2,16}=1.011$,
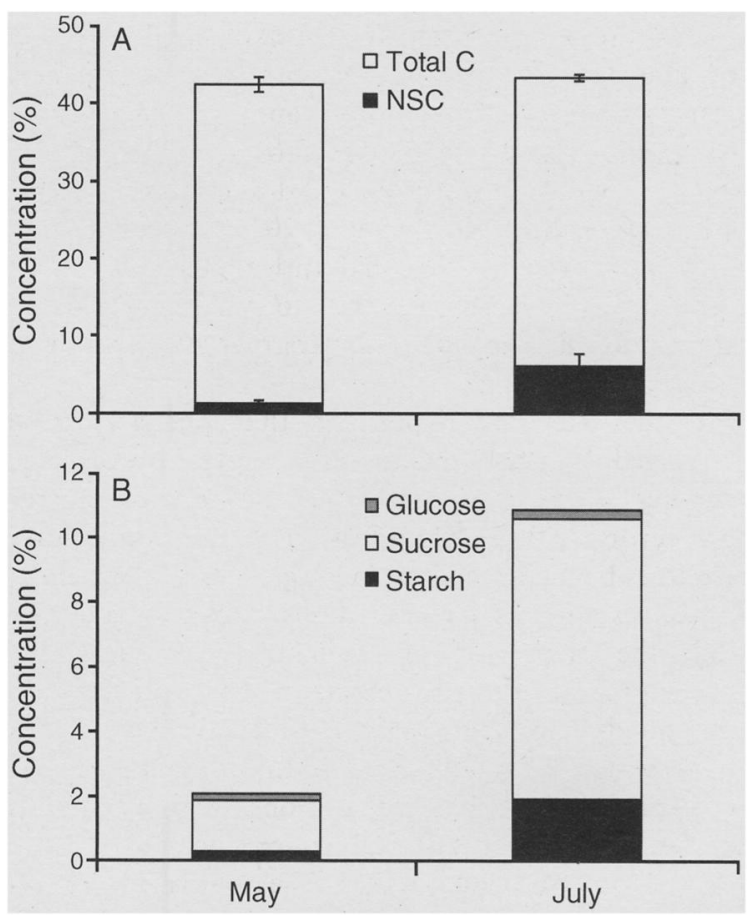

FIG. 2. (A) Change in nonstructural carbohydrate (NSC) concentrations in relation to total carbon concentrations for dormant plants. Data are averages of 2007 and 2008 seasons and are means and SE. Total carbon concentrations remained relatively constant as the proportion of carbon as soluble sugars (NSC) increased. (B) NSC dynamics by fraction for dormant plants. Data are averages of 2007 and 2008 seasons. Sucrose, the major transport sugar throughout plants, is the only fraction that significantly increased. 
$P=0.37)$, and plants did not significantly gain $\mathrm{P}$ over the growing season (ANOVA; stage $F_{1,55}=1.364, P=0.25$ ). No significant differences were detected among stages at the end of the growing season for either $\mathrm{N}$ or $\mathrm{P}(\mathrm{N}$ ANOVA; stage $F_{2,34}=1.923, P=0.18$, year $F_{1,34}=1.99$, $P=0.17$; P ANOVA; stage $F_{2,18}=0.016, P=0.98$ ).

\section{Discussion}

Our results indicate that stored nonstructural carbohydrates are associated with prolonged dormancy of mature plants. Although plants that remain dormant during the growing season do not have lower stored mineral resources ( $\mathrm{N}$ and $\mathrm{P}$ ) relative to plants that emerge aboveground, they do have lower nonstructural carbohydrates (NSC). Further, dormant plants do not gain or lose N or P while belowground. Surprisingly, despite being entirely belowground, dormant plants increase NSC concentrations during the growing season, and end with concentrations comparable to plants that had emerged. Our results are consistent with the hypothesis that plants enter prolonged dormancy due to a lack of stored resources (Shefferson et al. 2005a, 2006). In this case, dormant plants may remain belowground because they simply lack sufficient mobile carbon (C) to construct leaves. Alternatively, low sugar concentrations may interrupt developmental pathways for aboveground growth. Recent work with model systems amenable to laboratory and greenhouse study has highlighted the pivotal role of $\mathrm{C}$ compounds in signaling pathways for growth and development (Halford and Paul 2003, Rolland et al. 2006, Lee et al. 2007). Thus, the shortage of NSC in dormant plants may reflect a shortage of the raw material to build tissue, or an interruption in signaling pathways that allow plants to emerge aboveground.

In the past the hypothesis that plants entered prolonged dormancy due to low resource stores seemed puzzling. If a plant lacks the resources to emerge aboveground, how would it gain those necessary resources by merely staying belowground? In Astragalus scaphoides total $\mathrm{C}$ concentrations remained constant, while the proportion of available $\mathrm{C}$ increased. We speculate that dormant plants remobilized cell-wall compounds (e.g., hemicelluloses) into available forms, as suggested by Hoch (2007). In other systems, C starvation in tissues has been demonstrated to stimulate the degradation of cell-wall compounds (Lee et al. 2007). Dormant plants begin the season with low NSC values, do not photosynthesize, and likely incur metabolic costs during the summer due to higher temperatures. These conditions are likely to lead to $\mathrm{C}$ starvation, which could then trigger cell-wall degradation, and the subsequent release of sugars from cell-wall materials. Further research in this area could provide more insight into the role of $\mathrm{C}$ metabolism, and not just assimilation, in the life-history strategies of wild plants in the field.
We suspect that plants may enter dormancy because they lack key resources that they gain through remobilization. An alternative would be that plants gain resources from symbionts. In mycotrophic species such as orchids, plants may gain resources from mycorrhizal partners or other symbionts while they remain belowground (Gill 1989, Shefferson et al. 2005b, 2007). A. scaphoides does not have strong associations with mycorrhizal or rhizobial partners (E. Crone, H. Addy, and M. Rillig, unpublished data), so it is not likely to be gaining $\mathrm{C}$ from belowground symbionts. However, the potential for resource transfer in other species increases the plausibility of the idea that plants gain resources during prolonged dormancy. In mycorrhizal species, soluble $\mathrm{C}$ may be transferred either to mycorrhizae or from them (Gill 1989, Lesica and Steele 1994, Lesica and Crone 2007, Shefferson 2009). Orchids have particular mycorrhizal associations that usually result in a net gain of C for the plant, even while dormant (Gill 1989, Shefferson et al. 2005b, 2007, Shefferson 2009). However, species with arbuscular mycorrhizal (AM) associations (such as Silene spaldingii, see Lesica and Crone 2007), typically allocate $C$ to mycorrhizae in return for mineral nutrients. Such allocation could lead to low NSC and dormancy, if low NSC causes prolonged dormancy. Alternatively, if mineral nutrients, rather than NSC, limit emergence for AM plants, they may be able to gain those resources through mycorrhizal symbionts while dormant. The resource dynamics associated with dormancy for species with these symbiotic relationships deserve additional research.

Our results strongly point to a causal link between NSC and prolonged dormancy. However, as with any observational study, the link between NSC and dormancy could be due to a spurious correlation with other driving factors. For example, both NSC and the tendency to remain dormant could be associated with plant age; however, dormancy in A. scaphoides declines very weakly with age $(r=-0.048)$, whereas younger plants tend to have higher NSC concentrations (J. R. Gremer, unpublished data). Alternatively, local low resource availability around sampled plants could reduce NSC and also stimulate dormancy. However, dormancy in A. scaphoides is not strongly associated with environmental resource availability. We attempted to alter plant performance by adding supplemental water over three years (Crone and Lesica 2006) and supplemental $\mathrm{N}$ and $\mathrm{P}$ in 2007 (E. E. Crone unpublished data); neither affected the probability of prolonged dormancy (J. R. Gremer, unpublished analysis). As a third possibility, Morrow and Olfelt (2003) showed that Solidago missouriensis plants were most likely to be dormant after years of high herbivory, and it is plausible that herbivory would also affect NSC stores. At our field site $\sim 1 \%$ of plants are defoliated in any given year (J. R. Gremer, personal observation) and other consumers are 
rare, but $\sim 20 \%$ of plants go dormant in any given year. Therefore, we doubt that herbivory alone is the primary cause of prolonged dormancy in this species. Finally, we have no reason to suspect that some individual plants are inherently more likely to remain dormant than others; most bouts of dormancy last only one year in this species (Lesica 1995), and most plants in our 25-year monitoring study have gone dormant at least once (E. E. Crone and J. R. Gremer, unpublished data). Furthermore, we harvested dormant plants with visible flowering stalks from previous years, indicating that these plants had flowered in the recent past. Overall, our results do not appear to be confounded by specific environmental factors or plant age. However, stored carbon resources reflect the integrated effect of plant performance over time, including NSC depletion after flowering (Crone et al. 2009) and combined responses to environmental factors (Chapin et al. 1990, Wyka 1999, Crone et al. 2009). Our results suggest that low NSC reflects this integrated effect rather than the effect of any single external environmental factor. Further research is needed to investigate the link between environmental factors, NSC stores, and prolonged dormancy.

Overall, we did not detect a large cost of dormancy in terms of stored resources; we suspect dormant plants remobilize existing resources. However, this remobilization of structural carbon could carry a long-term cost. Studies that have investigated the demographic costs and benefits of prolonged dormancy have sometimes, but not always, reported long-term costs. For some species, prolonged dormancy decreased survival probability compared to plants that did not remain belowground (Hutchings 1987, Shefferson et al. 2003; but see counterexamples in Shefferson et al. [2005a], Shefferson [2006], and Lesica and Crone [2007]). Similarly, Shefferson et al. (2003) found that dormant Cypripedium calceolus plants were less likely to reproduce in the year following dormancy, while Lesica and Crone (2007) showed dormant Silene spaldingii were more likely than vegetative or flowering plants to reproduce the following year. It may be that, in some cases, remobilization of resources during dormancy carries a long-term cost in terms of future survival or reproduction, even if this remobilization is better than death. Alternatively, prolonged dormancy may have different metabolic consequences in different plant species.

Our results suggest that $\mathrm{C}$ storage may help explain why some individuals disappear belowground for one or more years, and provide the mechanism for their return. Low levels of mobile $\mathrm{C}$ are associated with remaining belowground, while remobilization of structural $\mathrm{C}$ during dormancy could be a mechanism that allows plants to come back up again. This suggests that prolonged dormancy may not be exclusively under environmental control but it is also under strong internal control. Further work, such as experiments that include manipulation of carbon stores, is necessary to fully understand the relationship between stored $\mathrm{C}$ and dormancy. It may be that individual variation in $\mathrm{C}$ gain, allocation, and metabolism can explain why some plants go dormant while others do not. Because the availability of mobile carbon compounds depends on environmental effects on $\mathrm{C}$ acquisition (e.g., drought or herbivory) as well as on internal $\mathrm{C}$ metabolism and subsequent effects on developmental pathways, our results can reconcile the two leading hypotheses for prolonged dormancy because carbon resources belowground may be under both external and internal control. To our knowledge, we document for the first time that carbon metabolism may be associated with life history strategies in a long-lived perennial plant in the wild. Because these strategies have important implications for population dynamics, our results may open exciting lines of research spanning from plant molecular biology to population ecology and evolution.

\section{ACKNOWLEDGMENTS}

The authors thank E. Miller, E. Lahr, and K. Hopping for their assistance in field and laboratory work. We also thank two anonymous reviewers for careful and valuable comments on the manuscript. This research was supported by the National Science Foundation (NSF DEB 05-15756 to E. E. Crone and A. Sala, NSF DEB 02-40963 to E. E. Crone) and the University of Montana (J. Schmautz Fellowship to J. R. Gremer).

\section{Literature Cited}

Amthor, J. S. 2000. The McCree-deWit-Penning de VriesThornley respiration paradigms: 30 years later. Annals of Botany 86:1-20.

Boyce, P. J., and J. J. Volenec. 1992. Taproot carbohydrate concentrations and stress tolerance of contrasting alfalfa genotypes. Crop Science 32:757-761.

Chapin, F. S., III, E. Schultze, and H. A. Mooney. 1990. The ecology and economics of storage in plants. Annual Review of Ecology and Systematics 21:423-447.

Crone, E. E., and P. Lesica. 2004. Causes of synchronous flowering in Astragalus scaphoides, an iteroparous perennial plant. Ecology 85:1944-1954.

Crone, E. E., and P. Lesica. 2006. Pollen and water limitation in Astragalus scaphoides, a plant that flowers in alternate years. Oecologia 150:40-49.

Crone, E. E., E. Miller, and A. Sala. 2009. How do plants know when other plants are flowering? Resource depletion, pollen limitation and mast-seeding in a perennial wildflower. Ecology Letters 12:1119-1126.

Crone, E. E., L. Polansky, and P. Lesica. 2005. Empirical models of pollen limitation, resource acquisition, and mast seeding by a bee-pollinated wildflower. American Naturalist 166:396-408.

Ehrlen, J., and K. Lehtila. 2002. How perennial are perennial plants? Oikos 98:308-322.

Gill, D. E. 1989. Fruiting failure, pollinator inefficiency, and speciation in orchids. Pages $458-481$ in D. Otte and J. A. Endler, editors. Speciation and its consequences. Sinauer Associates, Sunderland, Massachusetts, USA.

Halford, N. G., and M. J. Paul. 2003. Carbon metabolite sensing and signalling. Plant Biotechnology Journal 1:381398. 
Ho, L. C., and A. R. Rees. 1976. Re-mobilization and redistribution of reserves in the tulip bulb in relation to new growth until anthesis. New Phytologist 76:59-68.

Hoch, G. 2007. Cell wall hemicelluloses as mobile carbon stores in non-reproductive plant tissues. Functional Ecology 21: 823-834.

Hoch, G., M. Popp, and C. Korner. 2002. Altitudinal increase of mobile carbon pools in Pinus cembra suggests sink limitation of growth at the Swiss treeline. Oikos 98:361-374.

Hutchings, M. J. 1987. The population biology of the early spider orchid, Ophrys sphegodes Mill II, temporal patterns in behaviour. Journal of Ecology 75:729-742.

Kobe, R. K. 1997. Carbohydrate allocation to storage as a basis of interspecific variation in sapling survivorship and growth. Oikos 80:226-233.

Lee, E. J., Y. Matsumura, K. Soga, T. Hoson, and N. Koizumi. 2007. Glycosyl hydrolases of cell walls are induced by sugar starvation in Arabidopsis. Plant and Cell Physiology 48:405413.

Lesica, P. 1995. Demography of Astragalus scaphoides and effects of herbivory on population growth. Great Basin Naturalist 55:142-150.

Lesica, P., and E. E. Crone. 2007. Causes and consequences of prolonged dormancy for an iteroparous geophyte, Silene spaldingii. Journal of Ecology 95:1360-1369.

Lesica, P., and B. M. Steele. 1994. Prolonged dormancy in vascular plants and implications for monitoring studies. Natural Areas Journal 14:209-212.

Miller, M. T., G. A. Allen, and J. A. Antos. 2004. Dormancy and flowering in two mariposa lilies (Calochortus) with contrasting distribution patterns. Canadian Journal of Botany 82:1790-1799.

Miller, R. O., and J. Kotuby-Amacher. 1996. Western States Laboratory Proficiency Testing Program. Soil and plant analytical methods. Version 3.00. Utah State University, Logan, Utah, USA.

Mooney, H. A., and R. I. Hays. 1973. Carbohydrate storage cycles in two Californian Mediterranean-climate trees. Flora (Jena) 162:295-304.
Morrow, P. A., and J. P. Olfelt. 2003. Phoenix clones: recovery after long-term defoliation-induced dormancy. Ecology Letters 6:119-125.

Rolland, F., E. Baena-Gonzalez, and J. Sheen. 2006. Sugar sensing and signaling in plants: conserved and novel mechanisms. Annual Review of Plant Biology 57:675-709.

Shefferson, R. P. 2006. Survival costs of adult dormancy and the confounding influence of size in lady's slipper orchids, genus Cypripedium. Oikos 115:253-262.

Shefferson, R. P. 2009. The evolutionary ecology of vegetative dormancy in mature herbaceous perennial plants. Journal of Ecology 97:1000-1009.

Shefferson, R. P., T. Kull, and K. Tali. 2005a. Adult wholeplant dormancy induced by stress in long-lived orchids. Ecology 86:3099-3104.

Shefferson, R. P., T. Kull, and K. Tali. 2006. Demographic response to shading and defoliation in two woodland orchids. Folia Geobotanica 41:95-106.

Shefferson, R. P., J. Proper, S. R. Beissinger, and E. L. Simms. 2003. Life history trade-offs in a rare orchid: the costs of flowering, dormancy, and sprouting. Ecology 84:1199-1206.

Shefferson, R. P., et al. 2007. The evolutionary history of mycorrhizal specificity among lady's slipper orchids. Evolution 61:1380-1390.

Shefferson, R. P., M. Weiß, T. Kull, and D. L. Taylor. $2005 b$. High specificity generally characterizes mycorrhizal association in rare lady's slipper orchids, genus Cypripedium. Molecular Ecology 14:613-626.

Van der Heyden, F., and W. D. Stock. 1996. Regrowth of a semiarid shrub following simulated browsing: the role of reserve carbon. Functional Ecology 10:647-653.

Wyka, T. 1999. Carbohydrate storage and use in an alpine population of the perennial herb, Oxytropis sericea. Oecologia 120:198-208.

Zimmerman, J. K., and D. F. Whigham. 1992. Ecological functions of carbohydrates stored in corms of Tipularia discolor (Orchidaceae). Functional Ecology 6:575-581. 